\title{
CAPÍTULO 09: O USO DAS REDES SOCIAIS EM ÉPOCA DE PANDEMIA - UM ESTUDO DE CASO APLICADO EM QUATRO ESCOLAS TÉCNICAS ESTADUAIS DE PERNAMBUCO
}

\section{CAPÍTULO 09: EL USO DE LAS REDES SOCIALES EN TIEMPOS DE PANDEMIA - UN ESTUDIO DE CASO APLICADO A CUATRO ESCUELAS TÉCNICAS DEL ESTADO DE PERNAMBUCO}

\section{CHAPTER 09: THE USE OF SOCIAL NETWORKS IN PANDEMIC TIMES - A CASE STUDY APPLIED TO FOUR TECHNICAL SCHOOLS IN THE STATE OF PERNAMBUCO}

\begin{abstract}
Ana Elisabeth de Brito Alves ${ }^{1}$; Guilherme da Silva Andrade ${ }^{2}$; José Alisson de Oliveira ${ }^{3}$; Juliana de Brito Alves ${ }^{4}$;
\end{abstract} Nadiene de Paiva Brandão ${ }^{5}$

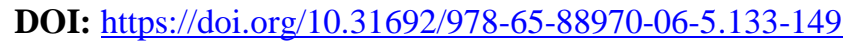

\begin{abstract}
RESUMO
O tema desenvolvido nessa pesquisa vem trazer um debate sobre o uso das redes no período do "pico" da pandemia da COVID-19. A partir de toda percepção sobre o comportamento anterior à pandemia desses jovens e fazendo um paralelo ao momento atual, vislumbrou-se uma necessidade de conhecer mais perto como os jovens pesquisados estão interagindo e usando as redes sociais, visto que agora eles estão cada vez mais conectados. Analisar se as redes sociais, nesse momento de pandemia representam para eles uma necessidade íntima, lazer ou dependência. Essa pesquisa tem a natureza qualitativa / quantitativa do tipo study of case, cujo campo (universo) são quatro escolas técnicas da rede estadual de ensino em Pernambuco (PE), os sujeitos envolvidos na pesquisa técnico são estudantes de 14 a 18 anos, que fazem o ensino de nível médio na modalidade integral nos cursos de Administração e Desenvolvimento de sistemas, os instrumentos utilizados foram um questionário elaborado pelo Google forms, contendo 21 perguntas elaboradas com o modelo de escala de Likert (mostrando a ordem de importância), dados quantificados foram considerados tratados no programa EpiInfo como modo de frequência. Após a análise dos questionários utilizou-se "rodas de conversa", debates por vídeo chamada pelo aplicativo Google meet. Assim, toda pesquisa, dados colhidos e debates, mostram que o virtual não deve ser visto como melhor nem pior, nem como substituto nem como efetivo, e sim uma ferramenta de transformação atual e que as redes sociais vieram para ficar, independente de formato, fama ou usabilidade.
\end{abstract}

Palavras-Chave: Redes sociais, Pandemia Covid-19, Estudantes da Rede Pública Estadual de PE, Dependência tecnológica.

\section{RESUMEN}

El tema desarrollado en esta investigación trae un debate sobre el uso de las redes durante el período "pico" de la pandemia OVID-19. De toda la percepción sobre el comportamiento prepandémico de estos jóvenes y haciendo un paralelo con el momento actual, se vislumbró la necesidad de conocer más de cerca cómo están interactuando y utilizando las redes sociales los jóvenes investigados, ya que ahora están cada vez más conectados. Analizar si las redes sociales, en este momento de la pandemia, representan para ellos una necesidad íntima, de ocio o de dependencia. Esta investigación tiene el carácter cualitativo / cuantitativo del estudio de tipo de caso, cuyo campo (universo) son cuatro escuelas técnicas de la red estatal de educación en Pernambuco (PE), los sujetos involucrados en la investigación técnica son estudiantes de 14 a 18 años, que hacen la educación secundaria en la

\footnotetext{
${ }^{1}$ Esp. Gerenciamento de Projetos, Pontifícia Universidade Católica de MG, anabritoalves@gm

${ }^{2}$ Grad. Administração, Faculdade de Ciências de Timbaúba-FACET, guilhermeandradempp

${ }^{3}$ Grad. Administração, Faculdade de Ciências de Timbaúba-FACET, alisson_oliveira0@

${ }^{4}$ Esp. Mídias da Educação, Universidade Federal de Pernambuco-UFPE, julianadeb

${ }^{5}$ Mestre, Instituto Superior de Leiria-ISLA, Portugal, nadienebrandao@ gmail.com
} 
modalidad integral en los cursos de Administración y Desarrollo de Sistemas, los instrumentos utilizados fueron un cuestionario preparado por formularios de Google, que contiene 21 preguntas preparadas con el modelo de escala de Likert (mostrando el orden de importancia), los datos cuantificados se consideraron en el programa EpiInfo como el modo de asistencia. Después del análisis de los cuestionarios, se utilizaron "ruedas de conversación", discusiones de video llamadas por la aplicación Google meet. Así pues, todas las investigaciones, los datos recopilados y los debates muestran que lo virtual no debe considerarse ni mejor ni peor, ni como un sustituto ni como eficaz, sino más bien como una herramienta de transformación actual y que las redes sociales han llegado para quedarse, independientemente del formato, la fama o la facilidad de uso.

Palabras Clave: Redes sociales, Pandemia Covid-19, Estudiantes de Red Pública Estatal de PE, Dependencia tecnológica.

\begin{abstract}
The theme developed in this research brings a debate about the use of networks during the "peak" period of the OVID-19 pandemic. From all the perception about the pre-pandemic behavior of these young people and making a parallel to the current moment, a need to know more closely how the researched young people are interacting and using the social networks was glimpsed, since now they are more and more connected. To analyze if the social networks, at this moment of the pandemic, represent for them an intimate need, leisure or dependence. This research has the qualitative / quantitative nature of the study of case type, whose field (universe) are four technical schools of the state education network in Pernambuco (PE), the subjects involved in the technical research are students from 14 to 18 years, who do the high school education in the full mode in the courses of Administration and Development Systems, the instruments used were a questionnaire prepared by Google forms, containing 21 questions prepared with the Likert scale model (showing the order of importance), quantified data were considered in the EpiInfo program as mode of attendance. After the analysis of the questionnaires, "conversation wheels" were used, video discussions called by the Google meet application. Thus, all research, data collected and debates, show that the virtual should not be seen as better or worse, neither as a substitute nor as effective, but rather as a tool for current transformation and that social networks are here to stay, regardless of format, fame or usability.
\end{abstract}

Keywords: Social networks, Covid-19 Pandemic, PE State Public Network Students, Technological Dependence.

\title{
INTRODUÇÃO
}

O tema desenvolvido nessa pesquisa trouxe um debate sobre o uso das redes sociais por jovens estudantes dos 14 aos 18 anos de quatro escolas técnicas estaduais do Estado de Pernambuco, no período do "pico" da pandemia da COVID-19. A vivência cotidiana mostra que as redes sociais ao longo do tempo, fez surgir nos indivíduos muitas necessidades, maioria delas são necessidades psicológicas, principalmente entre esses jovens, onde as mesmas redes se traduzem como um "casulo acolhedor", onde eles possuem com muito mais afinco as mudanças, as tendências, a curiosidade, embora que superficial, mas que vão aos poucos dirigindo suas demandas, e estas fazem todo sentido para uma vida "reclusa" e "virtual".

Os requisitos estabelecidos pela OMS (Organização Mundial de Saúde) e todo o protocolo guiado para a manutenção do distanciamento social, fizeram com que sociedade se isolasse em casa e ficasse muito mais tempo conectada à internet e utilizando uma infinidade 
de aplicativos, redes sociais e ferramentas tecnológicas para a nova experiência que se iniciava em meados de março de 2020. Criaram-se novos hábitos, costumes e mudança de cultura doméstica, aula remota, trabalhos em home Office, diminuição da prática de exercícios físicos e desregramentos alimentares, proporcionando uma "nova vida" que trouxe dessa forma novas perspectivas, umas positivas e outras nem tanto.

Mesmo em época de aulas presenciais, os jovens envolvidos na pesquisa, têm uma necessidade de estarem conectados, utilizando redes sociais com mais afinco e muitas vezes atrapalhando a aula, interrompendo os professores, prejudicando os colegas e em casa se ausentando da vida em família, esse contexto é vivenciado nas escolas públicas estaduais pesquisadas onde as mesmas não tem autonomia para proibir o uso errado (fora de hora) desses equipamentos eletrônicos.

A partir de toda percepção acerca do comportamento anterior à pandemia desses jovens e fazendo um paralelo ao momento atual, vislumbrou-se uma necessidade de se conhecer mais de perto como os jovens pesquisados estão interagindo e executando o uso das redes sociais, visto que agora eles estão cada vez mais conectados. Será que a realidade virtual mais do que nunca está se "impondo" à realidade presencial, ou se é apenas um mecanismo momentâneo de comunicação como tantos outros? O uso mais que o normal dessas redes sociais fará com que os estudantes substituam de vez o contato físico, já que são da geração que mais utiliza esses meios de comunicação? O uso exacerbado do virtual, para esses jovens, vem nessa época como uma necessidade, lazer ou dependência?

O objetivo geral dessa pesquisa é entender esse novo cenário na vida desses jovens e como eles estão se sentindo frente à nova realidade virtual. Como objetivos específicos, se buscou compreender: Conhecer as necessidades desses jovens permanecerem conectados às redes sociais; entender os sentimentos desses jovens ao buscarem tanto a permanência frente às redes sociais; analisar se as redes sociais, nesse momento de pandemia representam para esses jovens uma necessidade íntima, lazer ou dependência.

A decisão de pesquisar o tema com esse público é por trabalhar com o mesmo, mais perto e conhecer um pouco sua rotina e vislumbrar o que mudou radicalmente nos de março a setembro de 2020 (época dessa pesquisa). Visto que, o contato virtual passou a ter uma superioridade ao contato presencial, onde a conversa através de telas digitais ganhou amplo aspecto, e isso é um sinal de uma nova percepção de mundo. O público pesquisado é uma geração que "quase" só viveu a experiência virtual e para a mesma, não existe uma diferença gritante entre contato e intermediação, mas mesmo assim, sofreram um impacto emocional muito forte, o que os levou a mergulhar ainda mais no mundo digital, por motivos 
que serão apresentados na pesquisa de campo. Muitos desses jovens, mesmo antes da pandemia da Covid-19 preferiam ficar em casa a sair para um passeio urbano ou se encontrar com os amigos, mas ao mesmo tempo buscam afetividade, e isso nessa época de pandemia se intensificou; a permanência em casa se prolongou e também a dependência virtual, a carência emocional, a ausência de outros fatores importantes, etc. Por assim ser, nas redes sociais, os jovens expressam e deixam "sua marca", "vendem" suas opiniões e adquirem "amigos" e "seguidores".

Essa pesquisa tem a natureza qualitativa/quantitativa do tipo estudo de caso, cujo campo (universo) é quatro escolas técnicas da rede estadual de ensino em PE, os sujeitos envolvidos na pesquisa são estudantes de 14 a 18 anos, que fazem o ensino técnico de nível médio na modalidade integral nos cursos de Administração e Desenvolvimento de sistemas, os instrumentos utilizados foram debates por vídeo chamadas pelo Google Meet e após a roda de conversa foi aplicado um questionário elaborado pelo Google Forms, contendo vinte e uma (21) perguntas elaboradas com o modelo de escala de Likert (mostrando ordem de importância), cujos dados quantitativos foram tratados no programa EpiInfo como modo de frequência e serão demonstrados mais adiante nos resultados.

A contribuição desse artigo acerca do tema abordado é positiva e pertinente, possibilitando conhecer mais de perto o que ocorre com esses estudantes nesse momento de pandemia, como eles se comportaram frente ao cenário virtual e como eles se sentem, visto que o uso das redes sociais por esses estudantes possibilita a manutenção das atividades de estudos, ter acesso e informação acerca da pandemia e suas formas de proteção, e várias outras ações cotidianas, onde os estudantes conseguem manter certa rotina muito embora com algumas mudanças de hábitos e criação de outros vícios que podem ser ou não prejudiciais e serão apresentados mais adiante. A relevância do presente trabalho registra-se não apenas pelo seu objetivo geral, mas identifica-se, também, com o fornecimento de subsídios que permitam entender a dinâmica oculta dos relacionamentos e as conexões entre indivíduos que, voluntariamente, tornam-se propulsores de informação e grandes colaboradores organizações. É esse o intuito do trabalho apresentado.

\section{FUNDAMENTAÇÃO TEÓRICA}

\section{A educação técnica profissional de nível médio na rede estadual em Pernambuco}

A educação profissional vive um momento decisivo, mas não conclusivo. A procura por esse tipo de ensino atingiu patamares inéditos no Brasil e em Pernambuco, em que escolas 
técnicas estaduais vêm formando jovens e adultos, nas modalidades integral e subsequente e também à distância.

A iniciativa de implantar cursos técnicos em escolas estaduais vem suprir a carência da mão de obra técnica qualificada no estado de Pernambuco, onde cursos de diversas áreas são oferecidos a estudantes que cursam o ensino médio e técnico concomitantes em período integral durante três anos, e também estudantes que já concluíram o ensino médio, realizando apenas o ensino técnico profissional de nível médio no período de um ano e meio.

Em meio a pontos forte e fracos, o ensino profissional precisa ser melhor articulado, para não entrar em colapso e se perder do foco. Apesar de cada vez mais jovens estarem buscando aprender uma profissão, pode-se dizer que ainda falta um maior interesse do público-alvo. Segundo um agente responsável da consultoria Ceplan, em uma entrevista ao Diário de Pernambuco (2012) afirmou:

\begin{abstract}
"A dura verdade é que o desejo pelo diploma universitário, uma cultura secular no Brasil, mascara um preconceito enraizado na sociedade: de que ensino profissional é coisa de pobre. Em 2011, Pernambuco contava com 31.411 alunos matriculados em cursos técnicos, públicos e privados. Mas análise da consultoria Ceplan mostra que somente as demandas até 2014 de dois segmentos econômicos, a construção civil e a indústria metal mecânica, são de 32.500 novos trabalhadores por ano. O equilíbrio está distante. São 9 milhões de estudantes de Ensino Médio no Brasil."
\end{abstract}

Segundo dados do site da Secretaria de Educação do Estado, Pernambuco dispõe hoje (2020) de uma ampla rede de instituições que oferecem educação profissional gratuita em diversas habilitações. As novas cadeias produtivas aportadas neste Estado, nos últimos anos, vêm gerando uma demanda crescente por mão de obra especializada, trazendo dinamismo econômico e principalmente novas oportunidades para a educação técnica. Assim, o Governo do Estado de Pernambuco definiu como uma das suas prioridades a valorização, ampliação e estruturação da Rede Estadual de Educação Profissional e Tecnológica. Como resultado do esforço realizado na área, temos, atualmente, 28 Escolas Técnicas Estaduais em funcionamento, cerca de 27.480 estudantes matriculados nestas unidades e a oferta de 35 cursos em 23 municípios distribuídos em 12 Regiões de Desenvolvimento que compõem/o Estado. Os cursos são organizados por eixos tecnológicos: Ambiente e Saúde; Informação e Comunicação; Gestão e Negócios; Infraestrutura; e Controle de processos industriais.

De acordo com o site da SEDUC (Secretaria de Educação de Pernambuco), para assegurar e consolidar os avanços da educação técnica no Estado, desde 2009, a própria SEDUC, através da Secretaria Executiva de Educação Profissional, é responsável por formular, programar, acompanhar e avaliar as políticas estaduais de educação profissional em nível técnico. 
As opções de ensino técnico de nível médio permitem que todos os estudantes da rede estadual pelo Estado tenham a oportunidade de se qualificarem sem sair das suas regiões de desenvolvimento, garantindo formação específica e direcionada ao mercado de trabalho.

A história explica a barreira cultural quando o assunto é ensino profissional no Brasil. Logo, todas as iniciativas são válidas do ponto de vista governamental e social, mas ainda é sentida a falta de interesse dos próprios estudantes em formarem-se técnicos e também por parte de algumas empresas que escasseiam a oportunidade empregatícia.

\section{Formas de Oferta}

De acordo com as informações abaixo, retiradas do site da SEDUC, temos as formas de oferta do ensino profissional em escolas técnicas estaduais em Pernambuco.

- Integrada ao Ensino Médio em jornada integral: oferecida a quem já tenha concluído o ensino fundamental, sendo o curso planejado de modo a conduzir o aluno à habilitação profissional técnica de nível médio, vivenciando matriz curricular única com formação geral e profissional na mesma instituição de ensino;

- Subsequente ao Ensino Médio: oferecida somente a quem já tenha concluído o ensino médio;

- Concomitante ao Ensino Médio: ofertada nos cursos à distância.

\section{Modalidades de ensino profissional}

- Presencial: atende em sala de aula convencional estudantes egressos do ensino fundamental, preferencialmente da faixa etária de 14 a 18 anos, no ensino médio integrado em horário integral e estudantes ou trabalhadores, egressos do ensino médio, maiores de 18 anos, na forma de oferta subsequente;

- À Distância: atende estudantes, jovens e adultos na modalidade concomitante e subsequente, por intermédio do uso de tecnologias ma sala de aula, onde professores e alunos tem o contato mediado por interfaces.

\section{As redes sociais}

De acordo com Lemos (2019),

"As redes sociais são estruturas básicas de uma sociedade, são formadas pelas pessoas e seus relacionamentos; nossa rede social é formada pelos nossos relacionamentos diretos, como parentes, amigos e colegas de trabalho, e pelos relacionamentos que estes possuem com outras pessoas, de forma que todos os integrantes de um mesmo grupo social provavelmente estão direta ou indiretamente conectados." 
As redes sociais, segundo Marteleto (2001) representam "[...] um conjunto de participantes autônomos, unindo ideias e recursos em torno de valores e interesses compartilhados". As relações podem ser direcionais ou não direcionais. Ainda sob a ótica de Marteleto (2001),

\footnotetext{
"As redes nas ciências sociais designam normalmente - mas não exclusivamente os movimentos fracamente institucionalizados, reunindo indivíduos e grupos em uma associação cujos termos são variáveis e sujeitos a uma reinterpretação em função dos limites que pesam sobre suas ações."
}

Uma rede social refere-se a um conjunto de pessoas (organizações ou entidades) conectadas por relacionamentos sociais, motivadas pela amizade relação de trabalho ou troca de informação - uma representação formal de atores e suas relações. O fenômeno da conectividade é que constitui a dinâmica das redes e existe apenas na medida em que as conexões forem estabelecidas (MARTELETO, 2001). Portanto, segundo a mesma autora, a origem das redes sociais situa-se nas relações informais entre atores, capazes de organizar ações propositivas em uma esfera política. Estas ações, por sua vez, delineiam-se em função da dinâmica circunscrita pelo próprio movimento da rede.

O estabelecimento de vínculos entre os indivíduos é o que marca o surgimento de uma Rede Social Informal (RSI) numa organização, que Marteleto (2001) descreve como estruturas formadas de elos. Sob a ótica de Marteleto (2001), nas redes sociais, existe a valorização dos elos informais e das relações em detrimento da estrutura hierárquica.

Assim, a origem das redes sociais confunde-se com a origem da sociedade humana. " $\mathrm{O}$ que se convencionou chamar de redes hoje em dia são apenas ferramentas, que podem ajudar ou não na formação delas" (FRANCO, 2012).

Ainda para FRANCO (2012), "[...] entender a sociedade em rede é entender as redes, e entender as redes é entender a fenomenologia da interação. [...] Elas acontecem independentemente de nossas intenções de disciplinar o fluxo, guardá-lo ou congelá-lo".

\section{O uso das redes sociais e o acesso à internet}

A nova forma de comunicação tem afetado o dia a dia dos internautas. A quantidade de redes sociais é tão grande que os internautas gastam horas por dia para gerenciá-las. O usuário brasileiro passa em média 279 horas por mês na internet, boa parte desse tempo em sites de relacionamento, como Facebook e Instagram, segundo De Luca (2018) no relatório global da We are social publicado.

Hoje, as pessoas podem realizar várias atividades de sua casa, todas realizadas através da internet e suas redes sociais, vistas como ferramentas vitais nestes tempos, uma vez que, 
para o ser humano é fundamental se comunicar e manter o contato com o mundo.

Para muitos, as redes sociais se tornaram aliadas fiéis durante o confinamento, inclusive até para se "desconectar" do que está acontecendo, no entanto para outros, pode ser uma fonte de ansiedade (pela grande carga de informações dessa crise sanitária e até pela saturação de tantas atividades oferecidas), de frustração (por não possuir o que outros aparentemente têm), podendo até ser um sério problema de dependência.

Certamente, existem usuários mais ousados e usam as redes sociais para expressarem o que pensam, sentem e vivem, transformando essas ferramentas numa espécie de diário virtual. Esse tipo de usuário é o que passa mais tempo na internet: são pessoas que expõem as suas vidas, chegando na maioria das vezes a publicarem vídeos e fotos pessoais. Segundo Aros e Gomes:

[...] a informação é valiosa no sentido de que é a partir dela que um sujeito é capaz de se posicionar perante a sociedade. Quando esta é verdadeira e ancorada à realidade, manifesta-se a possibilidade, por parte de quem lê, de persuadir o outro, ver o corpo social de uma maneira mais crítica e construir um pensamento capaz de influir o mundo que o rodeia. Estar bem informado requer um exercício constante, ininterrupto e diário. (2017, p. 510).

Pelo exposto acima, a pesquisadora e professora do Programa de Pós-graduação em Saúde da Criança e da Mulher (PGSCM) do Instituto Nacional de Saúde da Mulher, da Criança e do Adolescente Fernandes Figueira (IFF/Fiocruz), Suely Deslandes fala em sua entrevista na revista 'Ciência e Saúde Coletiva' 2020, sobre o papel das redes sociais durante a pandemia:

\begin{abstract}
"Como indicam várias cartilhas e orientações de instituições de saúde, a internet nesse momento de isolamento social possibilita manter as interações com amigos, familiares e vizinhos. Mesmo aqueles que não estão podendo fazer o isolamento social, com a suspensão das aulas e de muitas frentes de trabalho, também estão mais tempo em casa e acessando mais a internet. $\mathrm{O}$ acesso à internet possibilita que muitos continuem a ter aulas, a manter atividades de trabalho, a participar de atividades culturais e artísticas e acessar suas redes de apoio. É através das redes digitais que se tem acesso a informações sobre a pandemia e as formas de proteção. A internet tem o papel fundamental de manter uma certa rotina e parâmetros de "normalidade" nesse momento de suspensão das atividades presenciais. Como cito em artigo de minha autoria com o professor Tiago Coutinho ("O uso intensivo da internet por crianças e adolescentes no contexto da Covid-19 e os riscos para violências autoinflingidas"), também publicado recentemente na Ciência e Saúde Coletiva, vemos que pela primeira vez o contato com o mundo "real" só é possível via conexão digital".
\end{abstract}

Fazendo um paralelo ao que diz Lipovstky (2010) "A vida cotidiana, em aspecto amplo, é caracterizado pelo aumento do tempo doméstico", e não só informações sobre a pandemia, mas, a internet e as redes sociais são os lugares de império do entertainement para os jovens, que vem procurando um "escape" nas telas, onde muitos desses jovens se isolam 
nesses espaços virtuais e são por excelência uma busca de prazer recluso, ou seja: Todo tempo livre em casa é atualmente ocupado pela "navegação nas redes sociais"

Suely Deslandes ainda completa:

\begin{abstract}
"Em primeiro lugar, o uso intensivo da internet pode gerar uma adição, um uso compulsivo, definindo uma dependência e centralidade do uso da internet em relação a qualquer outra ação cotidiana. A participação intensiva nas redes sociais também pode gerar um "excesso" de informação ou, em muitos casos, desinformação sobre a pandemia. O excesso de informação pode gerar ansiedade e a difusão da noção de um "medo global", com ênfase no número de mortes e previsões das curvas de contágio. Alguns autores sugerem que se busque definir um tempo determinado dentro da rotina para buscar informações, evitando assim estar "conectado o tempo todo". A lógica é de qualidade e não quantidade de informação. Assim, é melhor ter acesso a sites confiáveis (sites de órgãos oficiais de saúde) ao invés de ficar navegando em muitos sites que se contradizem e espalham notícias sem qualquer respaldo científico".
\end{abstract}

A priore, uma "rotina saudável" não é possível de ser definida, pois cada faixa etária/geração tem uma relação diferente e faz usos diversos das redes sociais. Para os jovens, por exemplo, a sociabilidade digital é essencial. Suely Deslandes argumenta:

\begin{abstract}
"Assim, a navegação on-line percorrerá caminhos diferentes entre games, busca de informação, interações com familiares/amigos/conhecidos, compra e contratação de serviços/mercadorias, entretenimento, aprendizagem escolar ou diversa, hobbies, etc. O que "faz bem" ou é "saudável" pode variar de acordo com a cultura, com os parâmetros de saúde mental e com a idade desse usuário. Os manuais da Organização Mundial da Saúde e do Unicef sugerem que os pais pactuem com seus filhos um tempo de uso da internet por dia, evitando que deixem de realizar outras atividades."
\end{abstract}

A sociabilidade digital é essencial à era contemporânea, ou seja, veio "para ficar" ainda que continue a sofrer constantes mudanças, de acordo com a incorporação de novas tecnologias. Porém, quando a quarentena se encerrar continuará a ser essencial. Contudo, a sociabilidade presencial, que permite a vinculação das corporalidades, a força dos sentidos, do toque, do abraço continuará a essencial da vida em comum, à vida humana.

\title{
METODOLOGIA
}

Essa pesquisa tem a natureza qualitativa/quantitativa do tipo estudo de caso, base em pesquisa bibliográfica; o campo (universo) de pesquisa, foram quatro escolas técnicas da rede estadual de ensino em $\mathrm{PE}$, os sujeitos envolvidos na pesquisa são estudantes de 14 a 18 anos, totalizando 343 estudantes, que fazem o ensino técnico de nível médio na modalidade integral nos cursos de Administração e Desenvolvimento de Sistemas; os instrumentos utilizados foram debates por vídeo chamadas pelo aplicativo Google Meet, que foi realizado após a aplicação de um questionário elaborado pelo Google Forms, contendo 20 
perguntas elaboradas com o modelo de escala de Likert (mostrando ordem de importância do menos importante ou "nunca" para o mais importante ou "sempre"), cujos dados quantitativos foram tratados no software EpiInfo como modo de frequência e serão demonstrados mais adiante nos resultados através de análise gráfica estatística.

\section{RESULTADOS E DISCUSSÃO}

É sabido que as tecnologias de informação e comunicação (TIC) contribuíram fortemente para democratização do acesso à informação, possibilitando a transposição de muitas barreiras, bem como o encurtamento de distâncias. Os resultados obtidos com a presente pesquisa tiveram dados surpreendentes, dentre as vinte perguntas que foram feitas aos estudantes, nove delas apresentam peso fundamental para o desdobramento da problemática e dos objetivos, correlacionando-se assim com a proposta justificada.

Na Tabela 01 - Sinto uma grande necessidade de permanecer conectado às redes sociais; Os dados percentuais mostram que 33,63\% sentem essa necessidade de forma razoável (3), ou seja, apresentou o maior número de respondentes (115 estudantes);

Tabela 01: Sinto uma grande necessidade de permanecer conectado às redes sociais If SINTO UMA GRANDE NZCISSSIDADE DE PERMLANECER CONECTADO AS REDES Frequency Percent Cum. Percent

\begin{tabular}{l|r|r|r|r}
\hline $\mathbf{2}$ & 15 & $4,39 \%$ & $4,39 \%$ & \\
\hline $\mathbf{2}$ & 40 & $11,70 \%$ & $16,08 \%$ & \\
\hline $\mathbf{4}$ & 115 & $33,63 \%$ & $49,71 \%$ & \\
\hline $\mathbf{5}$ & 94 & $27,49 \%$ & $77,19 \%$ & \\
\hline Iotal & 78 & $22,81 \%$ & $100,00 \%$ & \\
\hline
\end{tabular}

Fonte: Própria (2020).

$\mathrm{Na}$ Tabela 02 - Preciso de cada vez mais tempo para lidar com meus assuntos relacionados às redes sociais; os dados trazem um resultado de $31,49 \%$ sentem essa necessidade de forma também razoável (3), ou seja, contando com o maior número respondentes (108 estudantes);

Tabela 02: Preciso de cada vez mais tempo para lidar com meus assuntos relacionados às redes sociais IF SINTO UAIA GRANDE NzCISSIDADE DE PERMLANECER CONECTADO AS REDES Frequency Percent Cum. Percent

\begin{tabular}{|l|r|r|r|r|}
\hline 1 & 15 & $4,39 \%$ & $4,39 \%$ & \\
\hline 2 & 40 & $11,70 \%$ & $16,08 \%$ & \\
\hline 3 & 115 & $33,63 \%$ & $49,71 \%$ & \\
\hline 4 & 94 & $27,49 \%$ & $77,19 \%$ & \\
\hline 5 & 78 & $22,81 \%$ & $100,00 \%$ & \\
\hline Iotal & 342 & $100,00 \%$ & $100,00 \%$ & \\
\hline
\end{tabular}

Fonte: Própria (2020). 
Na Tabela 03 - $\underline{\mathrm{O} \text { tempo que antes eu destinava para estar conectado às redes sociais }}$ não me satisfaz mais. Preciso de mais tempo; Contou com 98 respondentes $(28,82 \%)$ a maioria na escala (1) que representa "nunca" ou "menos importante", significando que eles não precisam de mais tempo, cujo tempo que já ficam nas redes é o suficiente para suprir as suas necessidades.

Tabela 03: $\mathrm{O}$ tempo que antes eu destinava para estar conectado às redes sociais não me satisfaz mais. Preciso de mais tempo

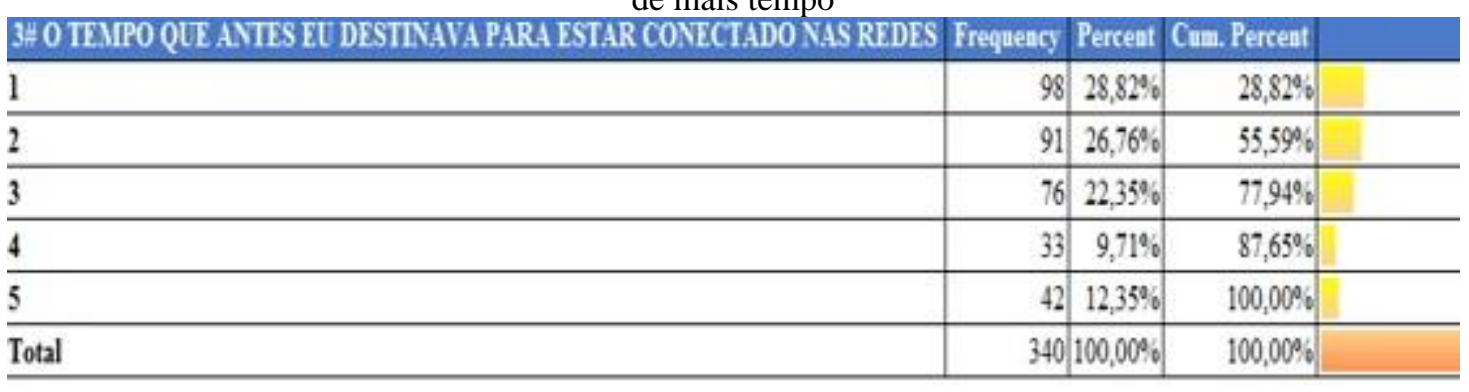

Fonte: Própria (2020).

Na Tabela 04 - Fico irritado se não consigo entrar nas redes sociais; Apresenta 28,45\% (a maioria 97 respondentes), afirmaram que "nunca" ficam irritados se não conseguirem entrar nas redes sociais, um indicativo positivo de que ficam tranquilos e que as redes sociais não é uma necessidade ou um vício. Já a minoria, 12,32\% (42 respondentes) afirmam que sente uma necessidade alta de estarem conectados às redes sociais e que ficam sim irritados e chateados se não conseguem o acesso.

Tabela 04: Fico irritado se não consigo entrar nas redes sociais

\begin{tabular}{|l|r|r|r|r}
\hline 6\# FICO IRRITADO SE NÄ0 CONSIGO ENTRAR NAS REDES SOCLAIS\# & Frequency & Percent & Cum. Percent & \\
\hline $\mathbf{1}$ & 97 & $28,45 \%$ & $28,45 \%$ & \\
\hline $\mathbf{2}$ & 74 & $21,70 \%$ & $50,15 \%$ & \\
\hline $\mathbf{3}$ & 79 & $23,17 \%$ & $73,31 \%$ & \\
\hline $\mathbf{4}$ & 42 & $12,32 \%$ & $85,63 \%$ & \\
\hline $\mathbf{5}$ & 49 & $14,37 \%$ & $100,00 \%$ & \\
\hline Total & 341 & $100,00 \%$ & $100,00 \%$ & \\
\hline
\end{tabular}

Fonte: Própria (2020).

Na Tabela 05 - Quando entro nas redes sociais perco a noção de tempo; A maioria estudantes pesquisados, $121(35,38 \%)$ na escala (5) afirmam que perdem totalmente a noção do tempo, significando que basta entrar nas redes para permanecerem mais tempo do que esperavam ficar, uma distância significativa em comparação com o menor índice de frequência que foi de 10,23\% que "nunca" perdem a noção de tempo quando entram nas redes sociais.

Tabela 05: Quando entro nas redes sociais perco a noção de tempo 


\begin{tabular}{|c|c|c|c|}
\hline 9: QUANDO ENIRO NAS RIDES SOCIAIS PERCO A NOCGO DE TEMIPO & Frequency & Percent & Cum. Percent \\
\hline 1 & 35 & $10,23 \%$ & $10,23 \%$ \\
\hline 2 & 39 & $11,40 \%$ & $21,64 \%$ \\
\hline 3 & 73 & $21,35 \%$ & $42,98 \%$ \\
\hline 4 & 74 & $21,64 \%$ & $64,62 \%$ \\
\hline 5 & 121 & $35,38 \%$ & $100,00 \%$ \\
\hline Total & 342 & $100,00 \%$ & $100,00 \%$ \\
\hline
\end{tabular}

Fonte: Própria (2020).

Na Tabela 06 - Não consigo me desconectar das redes sociais por vários dias; temos um percentual de muita atenção para o valor mínimo e máximo, onde o mínimo (ordem de importância 01 , ou "nunca") 25\% (85 respondentes) relataram uma negação à pergunta, não se sentindo viciados em redes sociais; Já uma diferença de apenas dez respondentes (75 estudantes, 22\%) afirmam que "sempre" não conseguem se desconectar por vários dias, se mostrando viciados realmente na interatividade.

Tabela 06: Não consigo me desconectar das redes sociais por vários dias

\begin{tabular}{|l|r|r|r|r|}
\hline 12 NAO CONSIGO MIE DESCONECTAR DAS REDES SOCLAIS POR VARIOS DLAS & Frequency & Percent & Cum. Percent & \\
\hline $\mathbf{1}$ & 85 & $25,00 \%$ & $25,00 \%$ & \\
\hline $\mathbf{2}$ & 69 & $20,29 \%$ & $45,29 \%$ & \\
\hline $\mathbf{3}$ & 60 & $17,65 \%$ & $62,94 \%$ & \\
\hline $\mathbf{4}$ & 51 & $15,00 \%$ & $77,94 \%$ & \\
\hline $\mathbf{5}$ & 75 & $22,06 \%$ & $100,00 \%$ & \\
\hline Total & 340 & $100,00 \%$ & $100,00 \%$ & \\
\hline
\end{tabular}

Fonte: Própria (2020).

Na Tabela 07 - Descuido de minhas amizades e/ou familiares por estar conectado às redes sociais; $189(55,43 \%)$ estudantes, afirmam que "nunca" fazem isso, ou seja, nunca descuidam das amizades e familiares, são presentes na vida de seus amigos e da família, e ficando distante do percentual dos que estão descuidando "sempre" do seu universo familiar e de amizades por conta da permanência e vício às redes sociais, representando a escala (5) de um total de 10 respondentes $(2,93 \%)$.

Tabela 07: Descuido de minhas amizades e/ou familiares por estar conectado às redes sociais

\begin{tabular}{|l|r|r|r|r|r|}
\hline 15: DESCUIDO DAS MIINHAS AMIZADES OU FAMIIIIARES POR ESTAR CONECTA & Frequency & Percent & Cuni. Percent & \\
\hline $\mathbf{1}$ & 189 & $55,43 \%$ & $55,43 \%$ & \\
\hline $\mathbf{2}$ & 73 & $21,41 \%$ & $76,83 \%$ & \\
\hline $\mathbf{3}$ & 45 & $13,20 \%$ & $90,03 \%$ & \\
\hline $\mathbf{4}$ & 24 & $7,04 \%$ & $97,07 \%$ & \\
\hline $\mathbf{5}$ & 10 & $2,93 \%$ & $100,00 \%$ & \\
\hline Total & 341 & $100,00 \%$ & $100,00 \%$ & \\
\hline
\end{tabular}

Fonte: Própria (2020).

Na Tabela 08 - Creio que seja um problema a intensidade e a frequência com que entro e uso as redes sociais; não acham que seja um problema a frequência com que entram nas redes sociais, representando $25,66 \%$ (87 respondentes), já 49 estudantes (14,45\%) afirmam 
que está sendo um problema a intensidade com que entram e navegam nas redes sociais, fazendo ao mesmo tempo justificar a pergunta da figura 07. Esses têm a consciência de que a permanência navegando nas redes sociais já está lhes trazendo problemas diversos, e mesmo assim não conseguem dimunuir o ritmo. Um dado importante nesse resultado é que a distância entre a escala é mínima e que o nível intermediário (3) também apresentou um número considerável de estudantes, em que julgam "razoável” e que acham já um problema a intensidade em que frequentam as redes sociais.

Tabela 08: Creio que seja um problema a intensidade e a frequência com que entro e uso as redes sociais

\begin{tabular}{|c|c|c|c|}
\hline 20" CREIO QLE SEJA UM PROBLEMA A INTIENSIDADE E A FREQUENCCIA COM & Frequency & Percent & Can. Percent \\
\hline 1 & 87 & $25,66 \%$ & $25,66 \%$ \\
\hline 2 & 86 & $25,37 \%$ & $51,03 \%$ \\
\hline 3 & 81 & $23,89 \%$ & $74,93 \%$ \\
\hline 4 & 36 & $10,62 \%$ & $85,55 \%$ \\
\hline 5 & 49 & $14,45 \%$ & $100,00 \%$ \\
\hline Total & 339 & $100,00 \%$ & $100,00 \%$ \\
\hline
\end{tabular}

Fonte: Própria (2020).

Na Tabela 09 - A maioria dos estudantes respondentes foram do gênero feminino, totalizando 204, do gênero masculino 133 e outros 2. Das 204 alunas respondentes, 73 $(35,78 \%)$ afirmam que possuem muitas atividades para fazerem fora das redes sociais, e que negam a afirmativa da pergunta "Não sei o que fazer quando estou desconectado das reses sociais", sendo assim NÃO dependentes da conectividade. Já 28 dessas estudantes $(13,73 \%)$ afirmam que não sabem mesmo o que fazer quando estão desconectadas das redes sociais, se sentem sozinhas e não pertencentes ao núcleo familiar e alegam que estão distantes das amizades, dos parentes e se relacionam apenas virtualmente e que essa virtualidade aumentou muito nesse período de pandemia, muito embora antes desse período já estavam muito conectadas. Um dado significativo na roda da conversa, após a aplicação do questionário, essas alunas que se mostram dependentes ao extremos das redes sociais acham normal, que não se sentem prejudicadas com a regularidade em que estão conectadas às redes sociais, e afirmam ser até melhor o convívio virtual do que o presencial, tendo uma visão positiva e um olhar tranquilo disso tudo.

Tabela 09: Não sei o que fazer quando estou desconectado das redes sociais e gênero 


\begin{tabular}{|c|c|c|c|c|c|c|}
\hline \multirow[b]{2}{*}{$21 \#$ QUAL SEU GENERO } & \multicolumn{5}{|c|}{ 5\# Näo sei o que fazer quando estou desconectado das redes socia } & \multirow[b]{2}{*}{ Total } \\
\hline & 1 & 2 & 3 & 4 & 5 & \\
\hline Feminino & 73 & 38 & 39 & 26 & 28 & 204 \\
\hline Row $\%$ & $35,78 \%$ & $18,63 \%$ & $19,12 \%$ & $12,75 \%$ & $13,73 \%$ & $100,00 \%$ \\
\hline Col\% & $54,89 \%$ & $59,38 \%$ & $67,24 \%$ & $70,27 \%$ & $59,57 \%$ & $60,18 \%$ \\
\hline Masculino & 58 & 26 & 19 & 11 & 19 & 133 \\
\hline Row\% & $43,61 \%$ & $19,55 \%$ & $14,29 \%$ & $8,27 \%$ & $14,29 \%$ & $100,00 \%$ \\
\hline $\mathrm{Col} \%$ & $43,61 \%$ & $40,63 \%$ & $32,76 \%$ & $29,73 \%$ & $40,43 \%$ & $39,23 \%$ \\
\hline Outros & 2 & 0 & 0 & 0 & 0 & 2 \\
\hline Row $\%$ & $100,00 \%$ & $0,00 \%$ & $0,00 \%$ & $0,00 \%$ & $0,00 \%$ & $100,00 \%$ \\
\hline $\mathrm{Col} \%$ & $1,50 \%$ & $0,00 \%$ & $0,00 \%$ & $0,00 \%$ & $0,00 \%$ & $0,59 \%$ \\
\hline IOTAL & 133 & 64 & 58 & 37 & 47 & 339 \\
\hline Row $\%$ & $39,23 \%$ & $18,88 \%$ & $17,11 \%$ & $10,91 \%$ & $13,86 \%$ & $100,00 \%$ \\
\hline Col $\%$ & $100,00 \%$ & $100,00 \%$ & $100,00 \%$ & $100,00 \%$ & $100,00 \%$ & $100,00 \%$ \\
\hline
\end{tabular}

Fonte: Própria (2020).

Dos 133 alunos (gênero masculino) respondentes, 58 (43,61\%) também possuem muitas atividades para fazer fora das redes sociais, e que negam a afirmativa da pergunta "Não sei o que fazer quando estou desconectado das reses sociais", sendo assim NÃO dependentes da conectividade, nem dependentes delas para interagir. Já 19 (14,29\%) desses alunos se afirmam muito dependentes das redes sociais, que realmente não sabem o que fazer quando estão sem conecção. O interessante é que diferente das alunas, eles apresentam uma certa preocupação com essa dependência às redes, e que ficam nas redes sociais e navegando por mais de 12 horas diárias e que gostariam de dimunuir a assiduidade; outros relataram que se sentem doentes e gostariam de se tratar desse "vício". Os outros dois estudantes (gênero outros) não se sentem dependentes da permanência nas redes sociais, e interagem muit bem sem elas. Se mostram firmes quanto a normalidade do uso e também não viciados nessas redes.

Partindo para as questões propostas de investigação que deram vida a essa pesquisa, temos os questionamentos seguintes e iremos desmembrá-los em três partes:

1. Será que a realidade virtual mais do que nunca está se "impondo" à realidade presencial, ou se é apenas um mecanismo momentâneo de comunicação como tantos outros? A partir dos dados da pesquisa, se verificou que ao mesmo tempo em que se excluem de uma convivência mais social e coletiva presencial, esses estudantes mostram o que são e o que não são, ou desejariam ser, na vida virtual, buscando uma "felicidade fictícia", muitas vezes acompanhada de uma solidão coletiva; muitos deles buscam por uma identidade de grupo seja esta facilitada ou não pelo universo virtual, afinal, só seguirão ou serão seguidos por pares afins. A realidade virtual é um fato existente e chegou para ficar, é sim um mecanismo de comunicação não mais 
momentâneo e sim perene, não que seja "imposto" ao momento atual, mas que veio envolver a sociedade como um todo com suas ferramentas; devido à sua necessidade real não deve ser visto como uma imposição e sim como uma necessidade facilitadora para que a comunicação flua o mais rápido e que possa envolver o maior número de usuários possíveis, onde foram mostrados nos dados da pesquisa que não se precisa de mais tempo para lidar com meus assuntos relacionados às redes sociais, pois o tempo que já desprendem é o suficiente (Tabela 2); que não sentem uma grande necessidade de permanecer conectado às redes sociais (Tabela 1), mostrando que existe vida além das redes; A pesquisa mostra a mínima adesão à necessidade de se ter mais tempo disponível para estar conectado às redes sociais, (Tabela 3) ou seja, não precisam de mais tempo. Sendo assim para os estudantes a resposta ao questionamento 1 é que: Não, a realidade virtual não vai se impor à vida presencial.

2. O uso mais que o normal dessas redes sociais, faz com que os estudantes substituam de vez o contato físico, já que são da geração que mais utiliza esses meios de comunicação? De fato é a geração que mais utiliza na história esses meios de comunicação virtual, mas como mostra a imagem 4, não ficam irritados se não estão em conexão com as redes sociais, mostra uma não dependência, sendo impossível uma substituição do contato físico, onde a grande maioria (Tabela 5) não perdem a noção de tempo quando entram nas redes sociais, mostrando que sabem administrar bem o uso do tempo para coisa úteis e necessárias, e que não apresentam a necessidade de ficar conectado por vários dias (Tabela 6), mostrando mais uma vez que a vida além das redes é a vida real.

3. O uso exacerbado do virtual, para esses jovens, vem nessa época como uma necessidade, lazer ou dependência? A Tabela 7 mostra um dado importante, em que os jovens não se descuidaram das amizades e da família nesse período de pandemia e isolamento social, onde a sua conexão às redes não os impedem da convivência e do cuidado com os que amam, não configurando uma "dependência" das redes sociais, e eu não é um problema a intensidade e a frequência com que entro e uso as redes sociais, indicando mais um lazer do que uma dependência, muito embora outros percentuais se autodeclarem dependentes, mas é a minoria dos estudantes pesquisados.

A intenção dos jovens pesquisados com relação às redes sociais heterogêneas demais para se traçar uma linha tênue entre os principais motivos, o que a pesquisa busca mostrar é a "prole" em pesquisa, por ser filha da revolução digital, se 
dessocializa gradativamente e abandonam cada vez mais as atividades vistas como tradicionais. A maioria dos jovens que participaram da pesquisa possui o gosto pelo "livre" o desejo de sair, de ver pessoas, de participarem de shows e festas de rua, mas, que todo esse desejo foi "trocado" pelo passeio virtual e quem já era "viciado" nessa conectividade ficou ainda mais preso a ela. A virtualidade em época de pandemia diminui os gastos desses jovens com entretenimento, alimentação e outros supérfluos, e fazendo uma ligação comparativa ao que fala Lipovstky (2010), "vive-se a era da cultura digital que cedeu lugar ao império do entertainement virtual".

\section{CONCLUSÕES}

As redes sociais são "consumidas" por esses jovens abruptamente, e em muitos casos esse consumo funciona como lazer, como fuga da realidade e também como um meio de buscar afetividade.

Continuaremos nos desdobrando entre as fronteiras cada vez mais borradas entre os mundos online e off-line. O que nos parece ainda um desafio imediato é o investimento numa educação digital, para que o uso do internet e consequentemente das redes sociais seja ético, para que as informações ali veiculadas sejam absorvidas de forma crítica e reflexiva e assim possamos usufruir das muitas possibilidades de comunicação, produção e disseminação de conhecimento, afeto, de lutas por direitos e mesmo de serviços e negócios, e não uma prisão, e não um adoecimento mesmo que inconsciente. As redes sociais são "consumidas" por esses jovens estudantes de maneira extremamente abrupta, e muitos deles não sabem o mal que podem causar a si próprios pelo seu uso exagerado; Alguns estudantes buscam "lazer" nessa permanência nas redes sociais, outros buscam interagir, mesmo que essa convivência seja ociosa, por divertimento ou por prazer, assim, toda pesquisa, dados colhidos e debates, mostram que o virtual não deve ser visto como melhor nem pior, nem como substituto nem como efetivo, e sim uma ferramenta de transformação atual e que as redes sociais vieram para ficar, independente de formato, fama ou usabilidade.

Todos os envolvidos na pesquisa aprenderam muito sobre ferramentas tecnológicas e outros usos para as redes sociais, como lives com professores dando aula, por exemplo; aprenderam que o IGVT serve como plataforma para postar vídeos sobre algum assunto mais extenso e o professor não teve outro meio para postar; aprenderam que o youtube é uma fonte riquíssima não só de entretenimento, mas, sobretudo de pesquisa acadêmica, e que essa transformação gera necessidades e uma delas é mostra-se presente no mundo, é interagir e se 
comunicar, é trocar experiências e expandir conhecimentos.

E encerramos com um ponto de vista de Harari (2011) no livro Sapiens, "há 70.000 anos, a chamada revolução cognitiva mudou a espécie humana para sempre", ou seja, a complexidade da linguagem, as redes de relações, transformou o cérebro humano e fizeram do Homo Sapiens um vitorioso, sobre toda a natureza.

\section{REFERÊNCIAS}

HARARI, Yuval Noah. Sapiens: Uma breve história da humanidade. 29a edição. Editora Harper, 2011.

LIPOVETSKY, Gilles. A Felicidade Paradoxal: Ensaio Sobre a Sociedade do Hiperconsumo. Lisboa: Edições 70, 2010.

MARTELETO, Regina Maria. Análise de redes sociais: aplicação nos estudos de transferência da informação. Ciência da Informação. Brasília, v.30, n.1, p. 71-81, Instituto Brasileiro de Informação em Ciência e Tecnologia, 2001.

RECUERO, Raquel: Redes sociais na Internet. Porto Alegre: Sulina, 2009.

Sites e outros autores pesquisados:

AROS; GOMES. A influência das redes sociais na comunicação humana. http://cortezze.com.br/a-influencia-das-redes-sociais-na-comunicacao-humana/>, Acesso em novembro de 2020.

DE LUCA. Cristina. Relatório global da We are social. https://porta23.blogosfera.uol.com.br/2018/02/05/brasileiro-passa-mais-de-3-horas-e-meiapor-dia-em-redes-sociais/>, Acesso em novembro de 2020.

FERREIRA, Suely. COUTINHO, Tiago. O uso intensivo da internet por crianças e adolescentes no contexto da COVID-19 e os riscos para violências autoinflingidas. http://www.cienciaesaudecoletiva.com.br/artigos/o-uso-intensivo-da-internet-por-criancas-eadolescentes-no-contexto-da-covid19-e-os-riscos-para-violencias-autoinflingidas/>, Acesso em 20 de setembro de 2020.

FRANCO, Augusto. A origem das redes sociais é a sociedade humana. Disponível em http://gazetaonline.globo.com/ >, Acesso em 22 de agosto de 2020.

LEMOS, R. Silvio; COSTA, A. Ricardo; JUCÁ, M. Paulyne; SILVA, M. Edeilson. Redes sociais. Disponível em https://sistemascolaborativos.uniriotec.br/wpcontent/uploads/sites/18/2019/06/SC-cap4-redessociais.pdf>, Acesso em novembro de 2020. 